\title{
AS RELAÇÕES ENTRE AS ESFERAS LAICAS E ECLESIÁSTICAS NA ARISTOCRACIA DA NORTÚMBRIA NO SÉCULO VIII
}

THE RELATIONS BETWEen the LAY AND CLERICAL ARISTOCRATIC WORLDS OF NORTHUMBRIA IN THE 8TH CENTURY

\author{
Renato Rodrigues Da Silva* \\ silvarrenato@gmail.com
}

Resumo: Este artigo propõe-se a analisar as relações entre a aristocracia clerical e a aristocracia laica na Inglaterra Anglo-Saxã, no período conhecido como longo século VIII. A principal hipótese deste artigo é que estes dois grupos também podem e devem ser pensados como parte de uma mesma camada social, sendo esta a aristocracia. Para demonstrar esta hipótese, o artigo iniciará discutindo como o medievalismo tratou a questão do mundo clerical e como no século XX a ênfase nas dinâmicas internas e estruturas internas ao mundo eclesiástico acabou por progressivamente desvincular este grupo de relações com grupos laicos. Em seguida, para demonstrar como este vínculo deve ser pensado, seguir-se-á a análise de dois estudos de caso em que são possíveis identificar processos de fundação e regência de mosteiros na Nortúmbria. Estes casos são os do mosteiro de Wearmouth, assim como a carta de Beda ao bispo Ecgberto.

Palavras-chave: História Medieval, Inglaterra Anglo-Saxônica, Aristocracia.

Abstract: This article analyses the relations between the lay and the clerical aristocratic worlds in Anglo-Saxon England during the long eighth century. The main hypothesis of this article is that these two groups can and must be addressed as part of the same social group, the aristocracy. In order to test this hypothesis, the article will address how medievalism in the $20^{\text {th }}$ century has studied the clerical sector. This will point out to the progressive detachment of the clergy from the lay world in terms of academic analysis. In order to prove the intimate link between lay and clerical world, two case studies will be presented. These two case studies will address the foundation and ruling of monasteries in Northumbria. The case studies are the monastery of the Wearmouth monastery, and the famous Bede's letter to the bishop Ecgberth.

Keywords: Medieval History, Anglo-Saxon England, Aristocracy.

\section{Introdução}

Este artigo propõe-se a analisar as relações entre a aristocracia clerical e a aristocracia laica na Inglaterra Anglo-Saxã, no período conhecido como longo século VIII. A principal hipótese deste artigo é que estes dois grupos também podem e devem ser pensados como parte de uma mesma camada social, sendo esta a classe dominante - a aristocracia. ${ }^{1}$ Para demonstrar esta hipótese, o artigo iniciará discutindo como o

\footnotetext{
* PhD pela University of Leicester, Mestrado em História pela Universidade Federal Fluminense. Atualmente é professor substituto na Universidade Federal de São Paulo.

${ }_{1}^{1}$ Para uma discussão mais alongada sobre a utilização de conceitos marxistas no medievo, ver WICKHAM, Chris. The other transition: from the ancient world to feudalism. Past \& Present, vol. 103, n. 1, 1984, p. 3-36; WICKHAM, Chris, Framing the Early Middle Ages: Europe and the Mediterranean 400-800. Oxford, Oxford University Press, 2005; WICKHAM, Chris. What has Marxism done for medieval history, and what can it still do. In: WICKHAM, Chris. Marxist History-Writing for the Twenty-First Century. Oxford: Oxford University Press, 2007, p. 32-48; BASTOS, Mário Jorge da Motta. Assim na Terra como no Céu...: Paganismo, Cristianismo,
} 
medievalismo tratou a questão do mundo clerical e como no século $X X$ a ênfase nas dinâmicas internas e estruturas internas ao mundo eclesiástico acabou por (em geral) desvincular este grupo de relações com grupos laicos. Em seguida, para demonstrar como este vínculo deve ser pensado conjunta e intimamente, seguir-se-á a análise de dois estudos de caso em que é possível identificar processos de fundação e regência de mosteiros na Nortúmbria. Estes casos são os do mosteiro de Wearmouth e a carta de Beda ao bispo Ecgberto.

O desenvolvimento do medievalismo analisou continuamente o papel social da Igreja e do mundo eclesiástico, direta ou indiretamente. No século XVIII, "anticlerical e antiaristocrático", a Igreja foi lida como um dos elementos principais para caracterizar a Idade Média como um período negativo (FRANCO JR, 2001, p. 17-18). Durante o o século XIX, a mudança de paradigma imposta pelo romantismo tendeu a idealizar o período medieval; a fé passou a ser tida como um porto seguro frente às mudanças e convulsões sociais que teriam sido provocadas pelo racionalismo (FRANCO JR., 2001, 19-20). No século $\mathrm{XX}$, a partir do desenvolvimento da história científica o fenômeno religioso, o mundo clerical e o papel social da Igreja foram (e vêm sendo) reavaliados e complexificados. Isso não implica, contudo, que haja apenas uma leitura sobre o tema. Como em qualquer área da disciplina histórica, há divergências nas abordagens sobre o tema. É necessário, portanto, avaliar como a historiografia vem abordando esta relação. Este é o próximo passo deste texto.

Entre a aristocracia laica e o mundo eclesiástico: historiografia

A reflexão sobre a afirmação da história enquanto ciência e do medievalismo enquanto campo científico está umbilicalmente ligada à figura de Marc Bloch. Uma de suas principais obras aborda o funcionamento da sociedade nos marcos feudais. "A Sociedade Feudal" é um volumoso livro que conta com dois tomos, sendo o primeiro dividido em duas partes e o segundo tomo em três livros (BLOCH, 2009). O total de páginas passa de quinhentas. Contudo, a seção dedicada à "Sociedade eclesiástica no feudalismo" somam

Senhores e Camponeses na Alta Idade Média. São Paulo: Edusp, 2013; PACHÁ, Paulo H. Estado e Relações de Dependência Pessoal no Reino Visigodo de Toledo (Séculos VI-VII). Tese de Doutorado. Niterói, UFF, 2015. Para uma discussão mais alongada especificamente sobre o conceito de classes sociais, ver WICKHAM, 2005, p. 154; LOVELUCK, Christoper. Northwest Europe in the Early Middle Ages, c. AD 600-1150: a comparative archaeology. Cambridge: Cambridge University Press, 2013. 
apenas nove páginas (da 383 a 391, na edição consultada). No âmbito quantitativo, Bloch não dedica grande fôlego à reflexão sobre a sociedade eclesiástica no mundo feudal.

A reflexão de Bloch está ancorada em uma abordagem já explícita na primeira frase desta seção. "Entre os clérigos e os leigos, a fronteira não era, na idade feudal, esta linha precisa e firme que a reforma católica, no tempo do Concílio de Trento, se esforçaria por traçar" (BLOCH, 2009, p. 383). Segundo Bloch, o clero era caracterizado por um conjunto de direitos particulares e por privilégios de jurisdições, sendo estes privilégios muito claramente definidos; o clero seria, portanto, uma "classe jurídica" (BLOCH, 2009, p. 383). Contudo, o clero também seria caracterizado por possuírem membros que estavam atrelados a hieraquias internas, com diferenças grandes de poder, prestígio e modos de vida; para Bloch, portanto, o clero "nada tinha duma classe social" (BLOCH, 2009, p. 383).

Bloch atenta para a divisão dentro da Igreja entre o clero secular (párocos, padres) e o clero regular (monges), sua interconexões e suas subdivisões internas. A ligação feita entre estes dois setores da igreja seria feita por cima, pelos prelados: abades, bispos e arcebispos (BLOCH, 2009, p. 384). Estes ocupariam o mesmo nível de poder que "os mais altos barões da espada" (BLOCH, 2009, p. 384). No que diz respeito à ocupação de cargos, o clero secular, contudo, teria produzido linhagens de padres. No que diz respeito à manutenção do patrimônio fundiário (terras) e à dominação do campesinato, o senhorio rural conjugava estes dois elementos e não conseguiu se quebrado sequer pela Reforma Gregoriana (BLOCH, 2009, p. 386). No que diz respeito à relação com os potentados locais, Bloch ressalta que a ocupação de cargos eclesiásticos seguia uma lógica (e) ritualística muito próxima daquelas do ritual feudo-vassálico (BLOCH, 2009, p. 387-8). Este ponto seria uma reafirmação de como o elemento feudal tinge com suas cores todas as demais relações daquela sociedade. Em outras palavras, na sociedade feudal, para Bloch, o elemento determinante das demais relações daquela sociedade é o feudalismo.

As reflexões sobre a organização da sociedade feudal e medieval foram também analisadas por Georges Duby. Em sua influente tese sobre a região do Maconnais, Duby defende que há uma profunda transformação da sociedade medieval por volta do ano 1000 (DUBY, 1953). Esta transformação está ligada à apropriação do poder de ban, expressão que ficou cristalizada na historiografia como "senhorio banal". Esta face do poder aristocrático seria a apropriação privada por parte de grandes aristocratas de prerrogativas públicas. Para 
o estudo que este artigo pretende realizar, é importante destacar que o principal acervo documental utilizado por Duby nesta tese foram os arquivos do mosteiro de Cluny, assim como os referentes as dioceses de Dijon e, naturalmente, Mâcon (DUBY, 1953). Também é vital destacar que para a tese de Duby, do ponto de vista economicossocial, a distinção entre senhorios possuía um corte que era não era o corte entre senhorios leigos e eclesiásticos. Em sua tese, a distinção dos senhorios era sobretudo se a natureza do senhorio era senhorio fundiário ou senhorio banal (DUBY, 1953).

Com o desenvolvimento do seu pensamento e carreira como medievalista, Georges Duby se interessou sobre outras dimensões sociais. Ao investigar a dimensão das mentalidades e do imaginário, Duby desenvolve um estudo sobre as três ordens do feudalismo (DUBY, 1994). Estas ordens seriam: os que trabalham (laboratores), os que fazem a guerra (bellatores) e os que rezam (oratores). Nesta investigação, o autor defende que estas ordens são esquemas mentais hierarquizantes; contudo, eles possuem a função de orientação da vida prática daquelas pessoas. Em outras palavras, a ideia da tripartição social é a forma pela qual a sociedade feudal escolheu para representar a si própria (DUBY, 1994).

Jacques Le Goff investiu em uma análise ainda mais centrada no papel das mentalidades e da dinâmica cultural como dínamo da estruturação e dinâmicas sociais. Para Le Goff, o cristianismo está em primeiro plano na cena histórica da Idade Média, e este protagonismo já se anunciava pelo menos desde o século IV (LE GOFF, 1980, p. 209). Segundo sua análise, há dois fenômenos significativos no que diz respeito a estruturação cultural na Idade Média. Na Alta Idade Média a massa camponesa se torna um grupo de "pressão cultural"; a consequência desta pressão é uma crescente indiferenciação cultural entre os laicos. Já o clero monopoliza o que ele intitula "formas evoluídas, e nomeadamente escritas, de cultura" (LE GOFF, 180, p. 208-9). Para Le Goff, a grande diferenciação social da Idade Média é entre laicos e eclesiásticos, e estes últimos possuem uma cultura impermeável à cultura popular (LE GOFF, 2013).

Outra perspectiva fundamental para entender a dimensão religiosa na Idade Média foi a pavimentada por Peter Brown. Ao longo de sua trajetória, Peter Brown foi responsável pela afirmação de dois grandes marcos sobre a passagem do mundo antigo para o mundo medieval. Estes dois grandes marcos amplamente estudados por Brown são: 1) o culto aos santos; 2) a concepção de "Antiguidade Tardia". Estes dois conceitos não são pensados de 
forma desconectada. Contudo, para este presente estudo, o ponto elementar é a questão da santidade. Para Brown, o(s) "homem(ns) santo(s)" (holy man) ganharam posição de proeminência no período que chamamos de "baixo império romano", tanto no ocidente quanto no Oriente (BROWN, 1971, p. 80-101). Estas figuras santas seriam herdeiras da relação de patronato do fim do período romano, sendo a figura de articulação entre uma (ou mais) determinada(s) comunidade(s) e o sagrado (BROWN, 1971). Se no período do alto império a expressão máxima do sagrado era o distante imperador, agora esta era a figura da divindade cristã. Contudo, apesar desta distância entre crente e o sagrado aparentemente ser maior do que anteriormente (em função da divindade cristã ser mais abstrata que a figura do imperador), a figura da pessoa santa acaba por encurtar este caminho. Segundo Brown, o culto à santidade expressa uma transformação mais profunda, que é o desejo de um acesso mais pessoal ao sagrado (BROWN, 1971). Este acesso ao pessoal também é expresso pela ressignificação do corpo neste período, e a proximidade com a figura santa seria expressa inclusive no acesso às relíquias destes santos (comumente pedaços do corpo da pessoa santa) (BROWN, 1971; BROWN, 1988). Mais recentemente, Brown tem abordado a relação entre riqueza, doação e religiosidade (no sentido de sentimento religioso) (BROWN, 2012; BROWN, 2015; BROWN, 2016). Contudo, em geral suas abordagens da esfera econômica se expressam de forma geralmente quantitativa ("ricos", "pobres"), sem grandes qualificações do significado destas expressões e dos mecanismos que as produzem de forma mais ampla. Esta característica é ainda mais marcante no estudo Through the eye of a Needle ("Pelo buraco de uma agulha", em tradução livre), no qual as riquezas dos aristocratas romanos são comparadas através dos séculos do baixo império, sem considerar com profundidade que o mesmo número de hectares e números de escravos podem significar coisas muito diferentes ao longo deste contexto (BROWN, 2012).

As mais influentes correntes historiográficas do século $X X$ foram responsáveis por aprofundar o entendimento a respeito do mundo eclesiástico. Da segunda metade em diante deste século, a partir das trocas interdisciplinares com a antropologia, houve um grande foco nas questões envolvendo mentalidades, a ideologia, o imaginário e as sensibilidades religiosas. Estas questões são importantes e fundamentais para o entendimento holístico do medievo. Como Le Goff anunciava belamente, "O homem não vive somente de pão, a história não tinha mesmo pão, [...] Era necessário descobrir na 
história uma outra parte. Essa outra coisa, essa outra parte, eram as mentalidades" (LE GOFF, 1995, p. 71). Contudo, também é fundamental investir em um entendimento que fundamente materialmente estas relações para compreender o fenômeno religioso e suas relações com o mundo laico de forma mais holística. Neste sentido, o próximo passo será pensar os fundamentos destas relações na Inglaterra anglo-saxã, para tentar compreender como estas esferas da aristocracia de relacionam e se (re)produzem. Para isto, investiremos em um aspecto do fenômeno religioso que as fontes permitem conhecer um pouco melhor: os mosteiros. Ao analisar estes, pensaremos basicamente no processo de fundação dos mesmos, assim como na ocupação dos cargos de regência dos mesmos.

\section{Mosteiros: fundações e trajetórias}

Wearmouth

A fundação por Bento Biscopo

A escolha por começar a exposição dos nossos estudos de caso por Wearmouth possui alguns significados. O primeiro deles é que ele antecede cronologicamente (673) os mosteiros fundados em nossos outros estudos de caso. O documento que narra sua fundação (a Historia Abbatum) também é o mais antigo dos documentos dentre os que serão tratados neste artigo (c. 715/716). O segundo motivo é que o mosteiro duplo de Wearmouth-Jarrow é tido por Beda, o Venerável, como um modelo de funcionamento e de santidade. Este caráter modelar não se dá pelo caráter duplo do mosteiro, mas pela dinâmica das relações que ocorriam entre eles. Este aspecto de mosteiro que deveria ser modelo fica ainda mais claro quando comparado com a "Carta ao bispo Egberto", o último documento produzido por Beda. O terceiro motivo é que é um dos poucos relatos que trazem uma narrativa de circulação de terras entre a aristocracia de forma mais clara.

A Historia Abbatum provavelmente foi redigida entre 715 e 716 (GROCOCK \& WOOD, 2013, p. xxi). A redação deste texto está inserido em uma lógica de comemoração das figuras fundadores do mosteiro. Este tipo de comemoração desempenhou um papelchave na elaboração do senso de identidade de um mosteiro (CUBITT, 2000). A Historia Abbatum também dialoga com as demais obras de Beda, na medidade em que ela se insere após uma série de comentários bíblicos, desenvolvimentos de formas de contabilizar o tempo, e mesmo uma homilia dedicada a Bento Biscopo (para ser lida anualmente), 
fortalecendo a ideia de que a Historia Abbatum também tem um importante caráter de formação de identidade local (GROCOCK \& WOOD, 2013, p. xxii).

A fundação do mosteiro é apresentada por Beda na Historia Abbatum. Este documento narra a história do mosteiro a partir dos seus abades. Esta historia começa da seguinte forma:

O pio servo de Cristo Biscopo, também chamado Bento, [foi] influenciado pela graça superior [e] construiu [um] mosteiro em honra ao mais bem aventurado [e] príncipel dos apóstolos Pedro, próximo à foz do rio Wear em [sua margem] norte. Egfrido, o rei venerável e mais devotado daquelas pessoas, ajudou ele [Biscopo] e doou terras [para Biscopo]. ${ }^{2}$

Ao narrar a trajetória mundana de Bento Biscopo, o fundador de Wearmouth, Beda diz que este possuía um coração já maduro mesmo na infância, e que já estava destinado a buscar recompensas maiores que apenas as terrenas. Assim,

com aproximadamente vinte e cinco anos, ele era um nobre a serviço do rei Oswiu, e recebeu como presente dele [Oswiu] a posse de terras correspondente ao seu nível [hierárquico]. Ele [Biscopo] desdenhava de posses perecíveis para que pudesse adquirir [posses] eternas, e menosprezava o serviço militar e sua recompensa corruptível; para que ele possa ser digno de lutar pelo verdadeiro Rei e para ter um reino eterno na cidade que fica acima. ${ }^{3}$

A passagem sobre a fundação de Wearmouth é um dos poucos textos do século VIII que chegaram aos nossos dias que retratam a lógica da doação de terras entre a aristocracia. A indicação é que, ao completar 25 anos de idade, um aristocrata teria seus esforços militares recompensados com o assentamento e autonomização a partir da doação de um lote de terra. Subentende-se que esta terra não é nua, mas juntamente à sua doação está subentendida um conjunto de pessoas capacitadas para torná-las produtivas (camponeses). O diferencial de Biscopo é que este decide que não irá casar, mas fundar um mosteiro na

\footnotetext{
${ }^{2}$ Religiosus Christi famulus Biscopus cognomento Benedictus, aspirante superna gratia, monasterium construxit in honore beatissimi apostolorum principis Petri, iuxta ostium fliminis Viuri ad aquilonem. iuuante se ac terram tribuente uenerabili ac piissimo gentis illius regee Ecgfrido. Beda, Historia Abbatum; In GROCOCK, Christopher e WOOD, lan N. (trad. and ed.), Abbots of Wearmouth and Jarrow. Oxford: Oxford University Press, 2013. p. 2175. As traduções que estão no corpo do texto foram feitas pelo autor do artigo, e a tradução desta Historia completa está em vias de publicação.

${ }^{3}$ cum esset minister Osuii regis, et possessionem terrae suo gradui competentem ilo donante perciperet, annos natus circiter uiginti et quinque fastidiui possessionem caducam, ut adquirere posset aeternam; despexit militiam cum corruptibili donatiuo terrestrem, ut uero Regi militare, regnum in superna ciuitate mereretur habere perpetuum [...] HA, 1.
} 
propriedade. Diversas observações podem ser traçadas a partir da fundação deste mosteiro. Porém, sob a ótica deste artigo convém abordar os dois aspectos abaixo.

Em primeiro lugar, o mosteiro foi fundado por uma pessoa nobre. O termo em latim é minister, que neste contexto pode ser traduzido como "guerreiro doméstico" (THACKER, 1982). E o uso do vocábulo minister não se refere apenas ao serviço de "guerreiro doméstico" qualquer, mas indica que este guerreiro está submetido diretamente à realeza (ROLLASON, 2003, p. 185). Em outras palavras, sua posição na hierarquia social garantia a Biscopo acesso direto à realeza - e ele era remunerado também pela realeza. 0 texto destaca que a terra que receberia como pagamento pelos serviços prestados à realeza é proporcional a seu status (possessionem terrae suo gradui competentem). Ou seja, considerando que sua origem é de alta extração social, a quantidade de terra recebida por ele deveria ser relativamente alta.

Em segundo lugar, é fundamental destacar o que a origem social (nobre) do fundador do mosteiro significou em termos de acesso a recursos. Esta origem permitiu a Biscopo acesso direto a pessoas de que ocupavam posições centrais de poder, rique e status, além de o inserir em redes de sociabilidade do auge da hierarquia social daquela sociedade. Se o mosteiro foi fundado em uma terra doada pelo rei Oswiu, este foi decorado por presentes oriundos de outros lugares, cedidos por outras pessoas que também possuíam riqueza móvel. Poe exemplo, Biscopo trouxe presentes de Roma em sua primeira peregrinação; presentes do papa Vitaliano em sua segunda peregrinação a Roma; livros que recolheu pelo continente; trabalhadores especializados em trabalho em pedra e em vidro na Gália; estes últimos tinham por objetivo que o mosteiro pudesse ser construído tal qual os prédios romanos que Biscopo havia visitado. (HA, 2; 3; 5)

Em outras palavras, Wearmouth só pode ser fundado, construído e decorado de forma realtivamente suntuosa em função do caráter aristocrático de seu fundador. Mas um elemento fundamental aparece quando pensamos além da fundação do mosteiro, e pensamos em sua inscrição no tempo. Por isso, analisaremos agora como se deu a sucessão da regência em Wearmouth. Ou, em outras palavras, analisar como o cargo de abade era alcançado e transmitido de uma pessoa a outra. 


\section{O processo de sucessão abacial em Wearmouth}

Após sua fundação, o mosteiro de Weamouth sofreu um acréscimo de terras, doadas pelo rei Egfrido (filho do rei Oswiu). Nos quarenta lotes adicionais, Bento enviou dezessete (17) monges e estabeleceu Ceolfrido como abade; um ano depois, construiu um mosteiro dedicado a Paulo. Este segundo mosteiro era o mosteiro de Jarrow. Wearmouth foi dedicado a Pedro, e Jarrow ser dedicado a Paulo representava a ideia de uma profunda ligação sagrada e inquebrável entre eles. Além disso, a Historia Abbatum ressalta como estes não poderiam ser separados e pensados (e administrados) como dois mosteiros separadamente. Segundo o relato de Beda,

assim como (para usar uma ilustração) o corpo não pode ser separado da cabeça, através da qual ele respira, e a cabeça não pode esquecer do corpo, sem o qual ela não vive, nenhum homem deve tentar de nenhuma forma separar estes mosteiros dos primeiros apóstolos, juntos como são em sua comunhão fraterna, [embora] separados [fisicamente] um do outro. $(H A, 7)$

Ao fundar o mosteiro de Jarrow, Biscopo indicou Ceolfrido como seu abade. Ao mesmo tempo, escolheu Eosterwino como abade do mosteiro de Wearmouth. Segundo a Historia abbatum, a necessidade de nomear abades para estes mosteiros se devia às frequentes peregrinações de Biscopo à Roma, e a incerteza de seu retorno. ( HA, 7) Do ponto de vista teológico, esta divisão era justificada a partir da indicação de que Pedro havia estabelecido dois bispos subordinados a ele, para atuar conforme as circunstâncias se fizessem necessárias. ${ }^{4}$ Beda deixa claro que a nomeação de Eosterwino "o colocou a cargo [do mosteiro] legitimamente [de acordo com] a regra [...]" ${ }^{\prime 5}$ Conforme Grocock e Wood observam, a presença da palavra iure (legitimamente) pode indicar que Beda estava respondendo a críticos, deixando claro que a nomeação de Eosterwino foi sim, canônica (GROCOCK \& WOOD, 2013, p. 39, n. 70). Mas quais críticas seriam estas?

A questão é que Eosterwino também é apresentado como um muito amado companheiro de armas de Biscopo (socia dilectissimis commilitionis). ${ }^{6}$ Eosterwino também era de origem nobre e, quando jovem, compôs o exército do rei Egfrido (filho do rei Oswiu)

\footnotetext{
4 Farmer aponta que estes seriam Lino e Cleto (de "Anacleto"), de acordo com o Liber Pontificalis. Mais detalhes sobre este caso estão em Beda, HE, II, 4. FARMER, The age of Bede, p. 194, n. 1. Wood e Grocock apontam que a busca de Beda por paralelos parecem uma justificativa, o que indicaria que havia alguma forma de oposição às ações de Biscopo. GROCOK \& WOOD, Abbots, p. 40, n. 72.

${ }^{5}$ [...] eidem monasterio regendir iure praefecit [...]. HA, VII.

${ }^{6}$ [...] ut quem solus non poterar laborem, socia dilectissimis commilitionist uirtute leuius ferret. HA, 8.
} 
(KOTZOR, 1981, p. 30). Além desta ligação a partir da mesma camada social, Eosterwino também era primo (por parte de pai) de Biscopo. (HA, 8; também VCA, 10, 18) Portanto, é possível que houvesse um questionamento corrente sobre a passagem da regência do mosteiro para alguém da mesma família, conforme apontam Grogock e Wood (2013, p. 39, n. 70).

Enquanto Eosterwino era abade de Wearmouth, Ceolfrido era abade de Jarrow. Mas Ceolfrido também possuía laços de parentesco com Biscopo. (HA, 13; VCB 16) A nomeação de Biscopo para a função de abade teria vindo em um bom momento, pois de acordo com a sua hagiografia anônima, Ceolfrido estava cansado das relações muito verticalizadas no mosteiro no qual estava inserido antes de ser convocado por Biscopo. Este mosteiro não é nomeado na fonte. No mosteiro no qual estava antes, Ceolfrido percebeu os "ciúmes e a amarga perseguição por parte de alguns homens de origem nobre" (BOUTFLOWER, 2012, p. 50). Ou seja, Ceolfrido foge de uma instituição que ele parecia condenar em função da ingerência da origem nobre em assuntos eclesiásticos. Contudo, Ceolfrido acaba abrigado e indicado à posição de abade em um mosteiro que é regido por sua família.

Ceolfrido foi sucedido por Sigfrido. Sigfrido foi o primeiro abade responsável pelos dois mosteiros que não era parte da família do fundador do mosteiro. Contudo, ele foi eleito abade pela primeira vez quando Biscopo estava viajando; antes de viajar, Biscopo havia deixado ordens para que não se elegesse alguém que fosse parente de Ceolfrido. (HA, 11; VCB 16) Grocock e Wood apontam que esta ordem foi dada para evitar que o irmão de Ceolfrido fosse eleito, e este irmão era visto como impróprio para ocupar este cargo (GROCOCK \& WOOD, 2013, p. xlix, baseando-se em HA 11, VC 16). Se o raciocínio de Wood e Grocok estiver correto, a ordem tinha a intenção de evitar o que parecia ser um desenrolar natural dos eventos para os monges e as demais pessoas daquele contexto. Beda reconhece os laços de parentesco entre Biscopo, Eosterwino e Ceolfrido, mas apenas para dizer que estes não eram importantes e que não garantiram a estes favores ou ascensão rápida na hierarquia eclesiástica. (HA, 8 e 13) Contudo, é muito difícil desconsiderar a conclusão de Grocock e Wood de que o mosteiro duplo foi regido por uma única família (GROCOCK \& WOOD, 2013, p. xlix). (GROCOCK e WOOD, Abbots, p. xlix) 
O estudo da fundação e da sucessão de Wearmouth (e, posteriormente, de Wearmouth e Jarrow) pode nos ajudar a elucidar as relações entre aristocracia leiga e eclesiástica. O mosteiro foi fundado por uma pessoa de origem nobre, a partir de seus recursos (terra, força de trabalho, conexões políticas, relações de dom e contra-dom etc). Sua contínua expansão e gestão também se constituiu a partir do acúmulo de relações construídas a partir da origem aristocrática do fundador do mosteiro. A sucessão de sua regência, administração e gestão foi realizada em âmbito familiar, seguindo modelos que são comparáveis (e em boa medida, congruentes) ao acesso a patrimônio no mundo laico. $\mathrm{E}$ a dinâmica dificilmente poderia ser outra, uma vez que estes abades têm sua origem na aristocracia laica. São as mesmas pessoas, as mesmas famílias. Todos têm a mesma origem social e comungam da mesma formação em termos de valores, perspectivas, experiências e expectativas.

Em outras palavras, mesmo com a ênfase de Beda nos ritos e observação de regras para a eleição de abades, é difícil escapar da conclusão de que houve uma continuidade de grupos familiares cognatos à frente deste mosteiro duplo. Beda parece consciente da dificuldade que comunidades religiosas enfrentam face a dinâmicas familiares que, em termos de regras e normas, deveriam ser excluídas da experiência monástica. Esta dificuldade está mais expressa no último documento redigido por Beda, a famosa carta ao bispo Egberto. É fundamental, portanto, passar à análise da mesma.

As críticas de Beda aos falsos mosteiros (Epistola ad Ecgbertum Episcopum - EEE)

A famosa epístola de Beda ao bispo Egberto (que posteriormente seria arcebispo de York) possui possibilidades de abordagem muito variadas. Este artigo irá focar no aspecto sobre a fundação de mosteiros e a circulação de terras no seio da aristocracia, seja ela leiga ou eclesiástica, assim como sobre as posições de poder e prestígio correspondentes.

A carta é fundamentalmente uma grande reclamação sobre o processo de doação (e, portanto, circulação) e acesso a terra na Nortúmbria, e como o que Beda percebia como uma dinâmica social saudável estava comprometida ou pelo menos não operando dentro do que se esperava da mesma. Muitos mosteiros do início do século oitavo não eram o que deveriam ser, de acordo com a carta: eles tinham o título de mosteiros, mas não possuíam 
qualquer traço de vida monástica. ${ }^{7}$ Os clérigos também havia se tornado gananciosos: bispos queriam dioceses maiores (maior jurisdição sob seu comando); clérigos de extração mais baixa queria pagamentos diversos. ${ }^{8}$ Beda diz que a ampliação da área de atuação de um bispo colocaria mais pessoas sob os cuidados do bispo do que ele poderia efetivamente cuidar; para resolver o problema, sugere que novos episcopados sejam fundados, usando a riqueza destes mosteiros "falsos" para tal. ${ }^{9}$ Para Beda, não apenas estas comunidades e estas posições eram mais ricas do que deveriam ser, mas também seu estilo de vida era um problema. Blair defende que tanto os comentários desta epístola de Beda quanto os comentários produzidos por Beda sobre Esdras urgem pela destruição das cartas de doação (ou diplomas de doação) dos mosteiros falsos ou "pervertidos" (o termo em inglês é perverted) (BLAIR, 2005, p. 111).

Para Beda, estes mosteiros eram mais próximo de grandes patrimônios fundiários seculares que de mosteiros. ${ }^{10}$ Como parte das reclamações sobre estes mosteiros que ele identifica como falsos, está a existência das scripta que garantiam a existência destes. Estas scripta seriam as cartas de doação, que infelizmente não chegaram ao nosso tempo (as referentes à região da Nortúmbria; para os demais reinos há algumas cartas ou diplomas que chegaram aos nossos dias). Segundo Beda, os homens leigos estavam utilizando estas cartas ou diplomas de doação e seus respectivos direitos para satisfazer sua luxúria (libidini). ${ }^{11}$ Estas doações garantiriam

Direitos hereditários sobre estas terras enquadradas nos diplomas régios, e [os aristocratas leigos] conseguiram que os privilégios destas fossem

\footnotetext{
7 [...] in monasteriorum ascripta uocabulum, sed nichil prosus monasticae conuersationis habentia, EEE, 10.

${ }^{8}$ [...] Si ergo illos gratis euangelium praedicare iussit, neque aurum vel argentum, uel aliquid pecuniae temporalis ab eis, quibus praedicabant, accipere permisit; quid rogo, illis qui his contraria gerunt, periculi immineat? [...]; [...] Sicque fit ut episcoporum quidam non solum gratis non euangelizent uel manus fidelibus imponant; uerum etiam, quod grauius est, accepta ab auditoribus suis pecunia quam Dominus prohibuit, opus uerbi quod Dominus iussit exercere contemnant; [...] Cum enim antistes, dictante amore pecuniae, maiorem populi partem qual ulla ratione per totum anni spatium peragrare praedicando aut circuire ualuerit in nomen sui praesulatus assumpeserit, satis exitiable et sibimet ipsi et illis quibus falso praesulis nomine praelatus est comprobatur concinnare periculum [...] ; [...] in saeculari uita habuerat retentare, uel sub praetextu uitae sanctioris illas quas non habuerat congregare diuitias [...] EEE, 6.

${ }^{9}[$ [...] synodica auctoritate transferantur atque in adiutorium sedis episcopalis, EEE, 10.

${ }^{10} E E E, 10-11$.

${ }^{11} E E E, 12$
} 
confirmados pelas assinaturas de bispos, abades, autoridades seculares como se fossem verdadeiros perante Deus! ${ }^{12}$

Estes diplomas possuem uma função essencial no que diz respeito às relações de produção e de propriedade. Antes de haver diplomas, a doação era feita em um regime chamado folcland ("terras do povo", em tradução livre). Este regime consistia na doação de terras e população campesina dependente por parte do rei a um aristocrata. Quando este morria, esta terra retornava à posse da realeza, que a redoava para outro aristocrata (possivelmente o filho do finado). Com a introdução dos diplomas de doação (para a fundação de mosteiros), a doação feita pelo rei passou a ser feita em regime perpétuo, e não revogatório (em tese). Este regime de propriedade baseado do documento escrito é chamado de bookland ("terras do livro" em tradução livre, no qual o "livro" representa o registro documental escrito). A princípio, as booklands parecem ter sido restritas para doações à Igreja. Porém, é bem notório como estes diplomas de doação se transformaram em uma ferramenta importantíssima ao longo do século oitavo. Justamente por esta importância que ela parece estar sendo apropriada por homens leigos.

O comentário de Beda vai além de uma simples reclamação sobre a criação de falsos mosteiros e do desvio do que seria a correta prática cristã. Beda também era um comentarista político, sob certos aspectos. De acordo com Beda, os guerreiros domésticos (ministri) e os serviçais (famuli) dos reis estavam se chamando ao mesmo tempo de abades (abbates), evidenciando sua entrada na igreja, mas sem abandonar os títulos de chefes locais (praefectos), ou nobres (thegns) ou servos do rei (famulos regis). ${ }^{13}$ Isso provavelmente indica que quem fundava estes mosteiros falsos eram pessoas com altíssima origem social, muito provavelmente com apoio régio (GROCOCK \& WOOD, 2013, p. liii). A doação da terra feita pelo rei, através do mecanismo dos diplomas régios, se tornava permanente; em outras palavras, a terra doada não retornava ao rei depois que a pessoa que a recebeu morria. ${ }^{14} \mathrm{~A}$ consequência é que "não há lugar nos quais os filhos dos nobres e dos guerreiros veteranos

\footnotetext{
12 [...] in ius sibi haereditarium regalibus edictis faciunt asscribi, ipsas quoque litteras priuilegiorum suorum quase ueraciter Deo dignas, pontificum, abbatum, et potestatum seculi obtinent subcriptione confirmari. EEE, 12.

${ }^{13}$ [...] ac praeualente pessima consuetudine ministri quoque regis ac famuli idem facere sategerint, atque ita ordine peruerso innumeri sint inuenti qui se abbates pariter et praefectos siue ministros aut famulos regis appelent, EEE, 13.

${ }^{14}$ Pra uma discussão mais ampla sobre os diplomas régios, ver DUQUE, 2018.
} 
consigam uma doação de terra". ${ }^{15}$ A consequência da incapacidade régia de remunerar guerreiros é que estes guerreiros deixam a Nortúmbria, indo a outros reinos que poderiam recompensar seus esforços, debilitando a capacidade demográfico-militar da Nortúmbria. Conforme Yorke e Higham já defenderam anteriormente, Beda era particularmente atento às necessidades da atividade militar e da defesa da Nortúmbria (YORKE, 2009, p. 12, 17; HIGHAM, 2003, p. 158-67). Beda parece ter mais apreço por um rei guerreiro como Ecgfrido (que está capacitado para defender a Nortúmbria) do que pelo pacífico e intelectual Aldfrido, que chegou a ser treinado por monges na Irlanda (Yorke, 2009). O cenário parece então desolador para Beda: "nem nobres nem guerreiros com poder secular podem defender nosso povo contra os bárbaros."16

Em outras palavras, o comentário de Beda traz consigo uma aguda percepção das contradições presentes em sua sociedade. A análise que a carta traz é a de que desvirtuar a função sagrada dos mosteiros possuía uma consequência muito palpável e concreta. Em outras palavras, a dúvida lançada sobre a natureza destes mosteiros (apontando eles como falsos) indica uma dinâmica social que acaba por tendencialmente indiferenciar o funcionamento do patromônio leigo do eclesiástico, do espaço sagrado do profano, do mundo eclesiástico do leigo.

A Historia Abbatum contém um relato de que mesmo o mosteiro tido por Beda como ideal, observador das regras monásticas, com dinâmicas separadas das do mundo leigo etc. era de certa forma uma propriedade familiar, cuja regência manteve-se dentro de uma mesma família. Este relato também indicava que as pessoas que ocupavam grandes cargos na Igreja eram oriundos de alta extração nobre. A "Carta para o Bispo Ecgberto" indica a consequência desta indistinção, e do desejo da aristocracia de ter acesso à uma forma de propriedade que garantia a manutenção da riqueza no seio da sua família sem chance de retornar ao tesouro régio.

Conclusão

A historiografia dedicada ao medievo desenvolvida ao longo do século XX tendeu a apresentar e destacar a importância das figuras eclesiásticas. A partir da influência de

\footnotetext{
${ }^{15}$ ut omnino desit locus ubi filii nobelium aut emeritorum militum possessionem accipere possint. EEE, 11.

${ }^{16}[. .$.$] neque illa milites siue comites secularium potestatum qui gentem nostrum a barbaris defendant$ possident.
} 
correntes representadas por Jacques Le Goff e Peter Brown, houve em fins do século XX uma abordagem que progressivamente pensava no setor eclesiástico como afastado ou mesmo separado do mundo laico.

$\mathrm{Na}$ Nortúmbria anglo-saxã, a difusão de mosteiros tornou-se um processo efervescente. Contudo, o processo de fundação, regência e sucessão monástica acaba por demonstrar que estes são regidos por membros da aristocracia. Os altos membros do clero têm sua origem na alta aristocracia. Em outras palavras, estes setores tem a mesma origem a acabam sendo ocupados por membros das mesmas famílias; estas famílias, portanto, concentravam formas diferentes de poder. Sagrado e profano, clerical e laico, o poder da Nortúmbria parece estar ancorado na proeminência da aristocracia, e no tanto de recursos que estas posições ofertam, sejam estes recursos materiais, simbólicos, de vínculos familiares ou de naturezas diversas. Sem levar em conta a posição de dominância da aristocracia nesta sociedade, qualquer análise da relação entre os mundos sagrados e profanos parecem parciais.

\section{REFERÊNCIAS BIBLIOGRÁFICAS}

FONTES PRIMÁRIAS:

BEDA, Historia Ecclesiastica Gentis Anglorum, trad. e ed. COLGRAVE, B. e MYNORS, R.A.B. Oxford: Oxford University Press, 1969. . Vita Cuthiberti, preface, B. Colgrave (ed.) Two Lives of Saint

Cuthbert: A Life by an Anonymous Monk of Lindisfarne and Bede's Prose Life (Cambridge, 3rd ed., 1985). (referida como VCB nas notas). . Historia Abbatvm, in Christopher Grocock and lan N. Wood (trad. e Ed.), Abbots of Wearmouth and Jarrow. Oxford: Oxford University Press, 2013. (HA nas notas). . Epistola Bede Ad Ecgbertvm Episcopvm, in Christopher Grocock and lan N. Wood (trad. E ed.), Abbots of Wearmouth and Jarrow. Oxford: Oxford University Press, 2013. (EEE nas notas)

BOUTFLOWER, D. S (trad.). Annonymous Life of Ceolfrid, Abbot of Wearmouth and Jarrow. Londres: Sunderland Hills \& Company, 1912.

HISTORIOGRAFIA:

BASTOS, M. J. M. Assim na Terra como no Céu...: Paganismo, Cristianismo, Senhores e Camponeses na Alta Idade Média. São Paulo: Edusp, 2013. 
BLAIR, J. The Church in Anglo-Saxon Society. Oxford: Oxford University Press, 2005.

BLOCH, M. A Sociedade Feudal. Lisboa: Edições 70, 2009.

BROWN, P. The Rise and Function of the Holy Man in Late Antiquity. The Journal of Roman Studies. vol. 61, 1971, p. 80-101.

The Body and Society: Men, Women, and Sexual Renunciation in Early Christianity. Columbia: Columbia University Press, 1988.

. Through the Eye of a Needle: Wealth, the Fall of Rome, and the Making of Christianity in the West 350-550 AD. Princeton: Princeton University Press, 2012.

The Ransom of the Soul: Afterlife and Wealth in Early Western Christianity. Harvard: Harvard University Press, 2015. Press, 2016.

Treasure in Heaven: The Holy Poor in Early Christianity. Charlottesville: University of Virginia

CUBITT, C. Monastic memory and identity in early Anglo-Saxon England. In: FRAZER, W. O.; TYRRELL, A. (ed.). Social Identity in Early Medieval Britain. Leicester: Leicester University Press, 2000, p. 253276.

DUBY, G. La société aux Xle et XIle siècles dans la région mâconnaise. Paris: A. Colin, 1953.

. As três ordens ou o Imaginário do Feudalismo. Lisboa: Editorial Estampa, 1994.

DUQUE, F. S. Os diplomas e a governança nos reinos Anglo-Saxões: Mércia e o Wessex entre os séculos VIII e IX. Dissertação de mestrado. São Paulo: USP, 2018.

FRANCO JR., H. A Idade Média: O Nascimento do Ocidente. São Paulo: Brasiliense, 2001. p. 17-18.

KOTZOR, G. (ed) Das altenglische Martyrologium. Munique: 1981.

LE GOFF, J. Cultura clerical e tradições folclóricas na civilização merovíngia. In: LE GOFF, Jacques. Para um novo conceito de Idade Média. Tempo, trabalho e cultura no Ocidente. Lisboa: Estampa, 1980, p. 207-219.

LE GOFF, J. As Mentalidades - Uma história ambígua. In: LE GOFF, Jacques \& NORA, Pierre. História: Novos Objetos. Rio de Janeiro: Francisco Alves, 1995. p. 68-83.

LOVELUCK, C. Northwest Europe in the Early Middle Ages, c. AD 600-1150: a comparative archaeology. Cambridge: Cambridge University Press, 2013.

HIGHAM, N. (Re-) Reading Bede - The Ecclesiastical History in context. Londres: Ashford, 2006.

PACHÁ, P. H. Estado e Relações de Dependência Pessoal no Reino Visigodo de Toledo (Séculos VI-VII). Tese de Doutorado. Niterói, UFF, 2015.

ROLLASON, D. Northumbria, 500-1100, Creation and Destruction of a Kingdom. Cambridge: Cambridge University Press, 2003.

THACKER, A. Some terms for noblemen in Anglo-Saxon England, c. 650-900. ASSAH 2, BAR Brit. Sr. (1982), p. 201-5. 
WICKHAM, C. Framing the Early Middle Ages: Europe and the Mediterranean 400-800. Oxford: Oxford University Press, 2005.

What has Marxism done for medieval history, and what can it still do. In: WICKHAM, C. (ed.). Marxist History-Writing for the Twenty-First Century. Oxford: Oxford University Press, 2007, p. 32-48.

YORKE, B. Rex Doctissimus - Bede and King Aldfrith of Northumbria. Jarrow: The Jarrow Lectures, 2009. 